\title{
MICROWAVE DEHYDRATOR: AN ENVIRONMENTAL FRIENDLY STEP TOWARD IMPROVING MICROWAVE DEMULSIFICATION OF PETROLEUM EMULSIONS
}

\author{
Souleyman A. Issaka ${ }^{1}$, Abdurahman H. Nour ${ }^{2}$, Rosli Mohd Yunus ${ }^{3}$, Azhari, H. Nour ${ }^{4}$ \\ ${ }^{1}$ Faculty of Chemical and Natural Resources Engineering, Universiti Malaysia Pahang \\ ${ }^{3}$ Faculty of Chemical and Natural Resources Engineering, Universiti Malaysia Pahang \\ ${ }^{3}$ Faculty of Chemical and Natural Resources Engineering, Universiti Malaysia Pahang \\ ${ }^{4}$ Faculty of Industrial Science and Technology, Universiti Malaysia Pahang
}

\begin{abstract}
In this research introduces a newly improved method of microwave dehydrator. A system consists of modified domestic microwave oven and silicon based chemical demulsifiers was used to dehydrate two types of petroleum crude oils from Middle East. Silicone based additives which claimed to be nontoxic are used in conjunction with the modified microwave oven. The currently available demulsification techniques that consist mainly of chemicals together with mechanical, heating and electrical methods have some drawbacks, since chemicals are costly and harmful to the environment, mechanical techniques such as gravity settling tank, hydro cyclone vessel, centrifugal separators, and steam stripping are large requiring more space, time and cost, electrical techniques almost always work in a very high voltage that can easily cause fire via short circuit. Therefore, the objective of this project is to introduce the Microwave Dehydrator (MD) as a step forward to the commercialization of the microwave treatment of petroleum based emulsions. This is to replace or reduce the use of chemical dehydrators in the oil field. Simulated experimental model emulsions of various crude oils were produced to mimic the real emulsions. From previous articles, the optimal parameters to produce w/o emulsions of heavy crude oils were $0.25 \%(\mathrm{v} / \mathrm{v}$ ) emulsifier's concentration (Span 80) with mixing speed of $1600 \mathrm{rpm}$ for 7 minutes mixing time. In this study, experimental stable emulsion were prepared from two different crude oils namely, Saudi Arabia (SA) and Kuwait, the water content in the emulsion was varied (20-80\% and 50-50\%), as well as the concentration of the additives (0.05 and 0.1\%), results was discussed in terms of temperature, heat generation, and dielectric properties as well as water resolution. The results of the this research showed that, for 50-50\% Kuwait oil emulsions, the optimal formulation was $0.1 \%$ additive and 2 minutes irradiation time gave the maximum water separation of $87 \%$, while for 20-80\% Kuwait oil emulsions, $0.1 \%$ additives and 2 minutes irradiation time had given the maximum separation of 52\%. Furthermore, for Saudi Arabia crude emulsions, 50-50\% w/o emulsions with $0.1 \%$ additive and 1.5 irradiation time had given the maximum separation of $85 \%$. While for 20-80\% w/o emulsions, $0.1 \%$ additive and 2 minutes irradiation time had given the maximum separation of $62 \%$. Fundamentally the basic mechanism behind the effectiveness of microwave demulsification is that the electromagnetic wave that induce the water molecules to move as trying to rearrange themselves with the wave in two distinct mechanisms, known as ionic conduction and dipole rotation that would eventually convert the wave energy into heat generated within the water molecules. These results proved that microwave dehydrator can reduce the usage of chemical demulsifiers, as well as processing time and environmental issues.
\end{abstract}

Keywords: Microwave dehydrator, Green demulsifiers, petroleum dehydration, petroleum emulsions, heavy crude oils, and Silicone demulsifiers

\section{INTRODUCTION}

Electromagnetic spectrum laying within $300 \mathrm{MHz}$ to $300 \mathrm{GHz}$ is known as microwave, which known to have electric and magnetic properties. When it is projected to materials, it obeys the optical rules of Transmission Absorption and reflection, depending upon the characteristics of the materials [17]. Hence the applied electromagnetic field will induce polarization effect to the medium.

The wave length varies from $1 \mathrm{~m}$ to $1 \mathrm{~mm}$, in accordance with aforementioned frequencies $(300 \mathrm{MHz}$ to $300 \mathrm{GHz})$. Beside heating and scientific research purposes some other frequencies are reserved for specific purposes including these of cellular phone, radar and television satellite communications by American Federal Communication commission (FCC), however the most frequently used frequencies for Industrial, scientific and medical (ISM) purposes are 915 and $2450 \mathrm{MHz}$, [22].

Microwave is commonly preferred in material processing over its conventional counter part due to its volumetric heating. The mechanism of heat transfer in conventional heating is diffusion from the surface of the material then to the bulk, while in microwave heating, the temperature gradient in different location within the sample is almost 
invariant, another important phenomenon is that different material possess different heating pattern, and that due to the variation in material's microwave absorption capacity which in turn depends on dielectric loss that depends on frequency [22].

\subsection{Equations of Heat Transfer in Microwave}

The general form of heat transfer equation consists of three principal forms which are conductive convective and irradiation form given bellow.

$$
q_{M W}=\frac{h A}{V}\left(T_{m}-T_{a}\right)+\frac{\varepsilon A \sigma}{V}\left[\begin{array}{c}
\left(T_{m}+273.15\right)^{4} \\
-\left(T_{a}+273.15\right)^{4}
\end{array}\right]+\rho C_{p}\left(\frac{d T}{d t}\right)
$$

Unless this is not the case in microwave heating, wherein heat is generated within the material and its transfer property is directly linked to the thermo-physical properties of material as reported by Curet and others, thus the detailed heat transfer mechanisms in microwaves will be explained in the following set equations.

The rate heat generation in material is expressed as

$$
\rho c_{p} \frac{\partial T}{\partial t}=\operatorname{div} \cdot(k \nabla T)+Q
$$

Where: $\rho$ and $c_{p}$ are density and heat capacity of sample being heated, $\frac{\partial T}{\partial t}$ rate of temperature increase and $\mathrm{Q}$ is the internal energy acquired by the sample from the dissipated microwave power and could be calculated for $\mathrm{Z}$ directed electromagnetic wave by an equation relating power drop from surface to bottom which is

$$
\mathrm{Q}_{(\mathrm{z})}=\frac{\mathrm{F}_{0}}{\mathrm{~d}_{\mathrm{p}}(\mathrm{z})} \exp \left(-\int_{0}^{\mathrm{z}} \frac{\mathrm{dz}}{\mathrm{d}_{\mathrm{p}}(\mathrm{z})}\right)
$$

$F_{0}$ : Microwave surface flux and $\mathrm{d}_{\mathrm{p}}$ is the penetration depth which is strongly related to dielectric properties of the sample designated as the distance at which the microwave represents $\frac{1}{e}$ of the surface power flux and its mathematical expression is:

$$
\mathrm{d}_{\mathrm{p}}=\frac{\mathrm{c}_{0}}{2 \pi \mathrm{f}}\left[2 \varepsilon^{\prime}\left(\left(1+\left(\frac{\varepsilon^{\prime \prime}}{\varepsilon^{\prime}}\right)^{2}\right)^{\frac{1}{2}}-1\right)\right]^{-\frac{1}{2}}
$$

While surface flux at the same conditions as Maxwell equations is calculated by the following relation.

$$
\mathrm{F}_{0}(\mathrm{x}, 0)=\frac{2 \mathrm{P}_{\text {surf }}}{\mathrm{ab}} \sin ^{2}\left(\frac{\pi \mathrm{x}}{\mathrm{a}}\right)
$$

Where $(a, b)$ are the dimensions of the wave guide
However, from Maxwell equation's perspective, the magnitude of microwave power absorbed by the dielectric samples can be estimated by the local electric field strength on the sample being treated as

$$
\mathrm{Q}_{\mathrm{abs}}=\omega \cdot \mathrm{E}^{2} \cdot \varepsilon^{\prime} \cdot \varepsilon^{\prime \prime}
$$

The electric field for plane wave propagation mode is solved by the following equation

$$
\nabla \times\left(\mu_{\mathrm{r}}^{-1} \nabla \mathrm{E}\right)-\left(\dot{\varepsilon}_{\mathrm{r}}-\mathrm{j} \frac{\sigma}{\omega} \varepsilon_{0}\right) \mathrm{k}_{0}^{2} \mathrm{E}=0(7)
$$

$\omega$ : Pulsation of microwave radiation $(\mathrm{Rad} / \mathrm{s})$

E: electric field intensity $(\mathrm{v} / \mathrm{m})$

$\varepsilon$ : Complex permittivity

$\sigma:$ electrical conductivity $(\mathrm{s} / \mathrm{m})$

$\mu \mathrm{r}$ : relative electromagnetic permittivity of material $(\mathrm{H} / \mathrm{m})$

$\mathrm{K}$ : thermal conductivity (w/m.K)

According to some previous researchers, in the above equation the radiation and convective terms are very minor, and that is because sample container has very low dielectric constant therefore it does not generate much of heat and hence most of the waves are transmitted through the glass sample container to the emulsion. The density and heat capacity of emulsion are calculated from the following mixing rules:

$$
\begin{aligned}
& \rho_{m}=\rho_{w} \phi+\rho_{o}(1-\phi) \\
& C_{p, m}=C_{p, w} \phi+C_{p, o}(1-\phi)
\end{aligned}
$$

Where:

$\rho_{m}, \quad \rho_{w}, \rho_{o}(\mathrm{Kg} / \mathrm{m} 3)$ Represent the densities of emulsion, water and crude oil respectively, while

$C_{p, m}, C_{p, w}, C_{p, o} \quad(\mathrm{kj} / \mathrm{Kg} . \mathrm{K})$ Represent the heat capacities of emulsion, water and crude oil respectively.

\subsection{Theory of Microwave Dehydration}

Different materials have different heating capabilities by the incident microwave energy. Hence for opaque materials, the waves are totally reflected, while in transparent materials they are transverse, but in dielectric materials, waves are absorbed and transformed to heat. However, introducing some specific metal powder to non conducting solvent would render them microwave active and they can be heated [18].

The treatment of crude oil emulsion is of major importance in the respective industries, since most of the world crude oil produced in the forms of emulsion. Water is normally a good microwave absorber because of it high dielectric properties, however in some rapports, at large samples the heat transfer in oil was faster than that in the water and that is imparted to the thickness of the oil, but this convention does not work with small sample. Hence for small sample, 
the heating rate of the water was faster [20]. Emulsion was first treated via microwave by Wolf who was first started the concept of microwave demulsification. Since then more and more researches have been devoted paramount effort to this field. The efficiency of microwave on emulsion was found to induce some effect on the treated emulsion such as, the increase in the temperature might leads to reduction in viscosity, and this will increase the mobility of the water droplet that will in turn neutralizes the zeta potential of the dispersed droplet beside breaking the hydrogen bonding that may exists between the water and the surfactant molecules. Beside that the electromagnetic wave is believed to increase the internal pressure of the water droplets leading to reduction of the interfacial film thickness [21]. Most of the aforementioned microwave affects depends on dielectric properties, emulsion composition, droplet size distribution, together with the operating conditions including temperature and frequency. Sample is assumed homogeneous, the initial temperature also assumed homogeneous, but thermophysical and dielectric properties are temperature dependent.

As reported earlier dielectric heating is a strong function of $\mathrm{pH}$, Viscosity, salt content, acid and water content [21]. Thus it is important to relate all of these parameters to assess the microwave separation. With regard to separation efficiency which can be estimated by sedimentations rate in the case of water-in-oil emulsion, the settling velocity of water droplets through oil is given calculated According to the force balance and Stoke's law as

$$
v_{w}=\left(\frac{\left.\rho_{w}-\rho_{o}\right) g * D^{2}}{18 \mu_{o}}\right.
$$

Where: D is the diameter of droplets. Similarly, if water is the continuous phase, the rising velocity of oil droplets through water is given by:

$$
v_{o}=\left(\frac{\left.\rho_{w}-\rho_{o}\right) g * D^{2}}{18 \mu_{w}}\right.
$$

The viscosities of oil and water ( $\mu_{o}$ and $\mu_{w}$ ) are very sensitive to temperature, in this regards, as temperature increases, viscosity decreases much faster than the density difference $\left(\rho_{w}-\rho_{o}\right)$ does. Therefore, the heating either by microwave or conventional, increases the velocity, $v_{o}$ or $v_{w}$ and consequently makes the separation of emulsion faster.

Besides that, microwave also found to induce molecular rotation of the polar droplets which may reduce or neutralizes zeta potential of emulsion [23]. Zeta potential is a layer of electrical charges suspends the droplets and prevents their movement and coalescence. Since water molecule is a polar, it rotates at a high frequency under microwave irradiation. The molecular rotation raises the temperature through friction, and also neutralizes the zeta potential by disturbing the orderly arranged electrical charges surrounding water droplets. Without the support of zeta potential and interfacial barriers surrounding water droplets are moved downward by gravitational force.

The advantage of applying microwave energy over the conventional heating is its ability to heat sample more uniformly than the conventional heating. Although in some cases local overheating may occurs causing Hotspot or thermal runaway within the sample, keeping in mind that crude oil consists of vast numbers of component that differ in their conductivity and polarity and ultimately in their absorptive patterns with asphaltene being the dominant and the major charge carrying component since it is the most polar constituent of the crude oil, and contents significant number of heteroatoms than the others constituent [19] [13].

Other researchers investigated the effects of system geometry and water to oil ratios on emulsion stability, the types of containers used in their experiment were non reflective and partially reflective ceramic-metal complex plates with emulsion being placed in the opened exposed part, then from the data the maximum power distribution (resonance R) is found by plotting the power calculated and plotted for various parameters including dispersed phase volume fraction, emulsion thickness and plate types. They found the averages power absorption for $\mathrm{o} / \mathrm{w}$ emulsion is greater in sample heated with reflective surface and decrease with increasing oil volume fraction. At the same time, the thermal runaway was estimated by plotting the difference between the maximum and minimum temperature of the sample (o/w emulsion) plotted versus irradiation time was found to increase with increasing dispersed phase volume fraction [26]. Numerous investigations have been done in the field of microwave heating and material processing, Christian and friends have studied the absorption mechanism for emulsion containing aqueous and nano droplets, and found that Microwave absorption is attributed to the types of ions, concentration as well as their polarization [27]. Others have studied the effect of microwave in treating industrial waste water emulsions and admitted that microwave can be used as an alternative to the existing demulsification methods, however addition of small amount of acid was reported to increase the efficiency, moreover the effect of aqueous phase composition on microwave absorption was investigated elsewhere [21]. N.Bjerdalen and friends have applied the microwave and ultrasonic techniques to treat the solid particles deposited at the petroleum well, since these particles consist mainly of asphaltene, resins and wax precipitated together with other solid particles such as silica, bentonite and gypsum. The parameters of concern were temperature, Viscosity, and concentration of crude oil. The microwave device used was Samsung Mini-Chef MW 1010c that had a frequency of 60 $\mathrm{Hz}$ and output power of $120 \mathrm{~V}$, the temperature measuring probe was of type Greenlee THH-500, while the ultrasonic device was Medson mysono 201 A19001213 that had power output of $15 \mathrm{~V}$ and frequency of $3.5 \mathrm{MHz}$, the crude sample 
was originated from SANTA BARBARA, the irradiation time for microwave was 80 and 180 seconds (s) for crude oil and asphaltene respectively, while for ultrasonic treatment it was varied as $30,60,180 \mathrm{~s}$, results proved that microwave irradiation could elevate the temperature of petroleum crude oil and asphaltene and decrease the viscosity while with ultrasonic treatment the viscosity was observed to increase with increasing the irradiation time [11]. Abdurhaman and colleagues have compared the separation of water from crude oil by using conventional heating and microwave heating; the study was carried out on two different types of crude oils, and two different water to oil ratios of $30-70 \%$ and $50-50 \%$ w/o emulsions that were prepared by mixing the two phase vigorously via the standard three blade propeller at mixing speed of $1800 \mathrm{rpm}$ at ambient temperature for $5 \mathrm{~min}$, three types of emulsifiers namely Low sulfur wax residue (LSWR), Triton-x100 and Span 83 were used to produce the most stable w/o emulsion. For demulsification, Elba domestic microwave oven was used and the temperature profile of the sample was monitored using three thermocouples that were inserted in the sample at different location (Top, Middle and Bottom), microwave processing time was varied as $30,60,90,120,150,180,210$ $\mathrm{S}$, their results revealed the effectiveness of microwave heating over the conventional heating in breaking w/o emulsions [2].

Vladan Rajakovic and coworkers have used the combined Freeze/Thaw and microwave irradiation method to split the pure oil, from oil-in-water emulsion that was originated from metal working oil, the splitting process was carried out via the ultra-freezer device at three distinct temperature of $20,-40$ and $-600 \mathrm{C}$, for a processing or freezing duration of $10 \mathrm{~h}$, then thawed back in Air at $200 \mathrm{C}$, after that placed in water bath at $400 \mathrm{C}$ or microwave at $950 \mathrm{C}(800 \mathrm{w}, 2450$ $\mathrm{MHz}$ ), however their results showed that the effectiveness of the freeze/thawing and microwave demulsification techniques depend mainly on the oil contain of the emulsion sample, freezing time and thawing steps, thawing time, indeed microwave also believed to induce molecules to acquire more energy because of super heating and increased reaction rate, and thus microwave demulsification is proved to be the most effective method in breaking emulsions [14].

A. H. Nour and coworkers have investigated the batch microwave oven with $2450 \mathrm{MHz}$ in treating and breaking w/o emulsion, their experimental emulsion was prepared using commercially emulsifiers, the commercial emulsifiers used in their study were Triton-X100 and Low Sulfur Wax Residue (LSWR), their experimental emulsion was consisted of $20-80$ and $50-50 \%$ water to oil ratio, the crude used was given by PETRONAS (Malaka refinery), the mixing power was provided through by the standard three blade propeller, the mixing speed was fixed at $1800 \mathrm{rpm}$, at ambient temperature for an emulsification time of $8 \mathrm{~min}$, however their comprehensive study have proved that microwave can provide very fast and uniform heating and have a very strong potential to be used as an alternative demulsification technique for petroleum emulsion treatment [4].
Hyder A. Abdulbari and friends have studied the stability as well as microwave demulsification of petroleum emulsion; the stability was done by assessing the effectiveness of Sorbitan monooleate (Span 83), Triton-x100, Low sulfur wax residue (LSWR), and sodium dodecyl sulfate (SDDS), the parameters of interest were; the surfactant types, surfactants concentration, water volume fraction in the emulsion (10-90\%), emulsification temperature and agitation speed, the raw crude petroleum oil were originated from Iran and Malaysian oil fields. Emulsions were prepared through the agent in oil method and mixture was agitated vigorously via the three blade propeller at emulsification speed of $1600 \mathrm{rpm}$ at ambient temperature, the demulsification experiment was carried out using Elba microwave oven whose power output was 900 Watt and frequency of $2450 \mathrm{MHz}$. Their results also showed that microwave treatment gave rapid separation over the conventional gravitational settling [7]. Montserate Fortuny and colleagues have investigated the some important parameters for microwave demulsification, namely salinity, temperature, water content and $\mathrm{pH}$. Their experimental emulsion was prepared by mixing the crude oil with saline water and homogenized using two steps emulsification techniques, thus in the first step the mixture was mixed by simple hand shaking, then certain amount of water was added in a drop-wise fashion while the mixing is going on, then in the second step the system was vigorously mixed using the ultra-turax T-25 homogenizer fitted with a S25$25 \mathrm{G}$ dispersing tool, the water volume fraction was varied as $(25,35,45)$ the mixing speed and time were fixed at 17500 for $10 \mathrm{~min}$, the demulsification processes were performed using the commercial microwave with a processing time of $15 \mathrm{~min}$. from their results it was observed that increasing the microwave power could increase the demulsification process, beside that high water contained emulsions were found to give high separation efficiency and that is because of the dielectric heating, also high salt content or high $\mathrm{pH}$ had reduced the demulsification rate, indeed the best separation rate was observed with emulsion having water volume fraction of $45 \%$ and $\mathrm{pH}$ of 7 [21]. Rosli M. yunus and colleagues have conducted a laboratory experiment to examine the performance of microwave heating technique in breaking water-in-crude oil emulsion in comparison with the conventional demulsification techniques. However, their results had concluded that microwave gave better separation than the conventional beside that microwave does not need any chemicals addition and could be used as an alternative green technique to treat petroleum emulsions [10]. A. N. Ilia Anisa and colleagues have also used the microwave demulsification techniques to treat w/o emulsions and optimize the operating conditions to fix the best operating conditions for microwave demulsification by using the RSM software [1] [15].

Lixin Xia and colleagues have studied the stability of crude oil emulsion and its relation to the presence of Asphaltene and resins (the natural surfactants), followed by microwave demulsification, their experimental emulsion was produced by using jet kerosene as oil phase mixed with certain 
amounts of asphaltene and resin that was extracted from Daqing crude oil (China), they varied the concentration of asphaltene in the bulk emulsion in the range between 0.3 to $0.9 \mathrm{w} / \mathrm{w} \%$, and that of the resin was in the range of 1-4 $\mathrm{w} / \mathrm{w} \%$, the mixing process was performed by simple hand shaking. The demulsification process was carried out by using either oil bath at $900 \mathrm{C}$, or microwave oven or microwave oven with power output of 850 watt and 2450 $\mathrm{MHz}$, their results revealed that stability was strongly depended on the amount of the asphaltene and resin in the daqing crude oil, and that is because the adsorption of these interfacial active components at the interfaces is believed to form a mechanical film between the droplets, also microwave demulsification had given better separation result compared to the conventional demulsification methods [8].

Abdurahman and colleagues have proposed a continuous microwave demulsification method for water-in-crude oil emulsion and found that the temperature rise within the sample at given location was linear with respect to time and the rate of temperature increase of emulsion decreases at elevated temperature due to the decrease of dielectric loss of water[3]. In this research, microwave oven was modified by drilling a hole of $26 \mathrm{~cm}$ diameter at the top surface, and the rounded bottom flask container was used to carry the sample.

The chemical additives that used were chosen after massive literature survey on the current commercial surfactants used in the oil field.

With regard to the chemical additives, most of the commercial additives contain long chain of polymers such as aromatics, amines and sulfonic acid salts that are not very safe from the environmental and economic prospective [24]. Dalmazzone had reported that silicone demulsifiers are rather expensive but the current environmental issues may render them useful in the future, because they are non-toxic and non-harmful to the environment [5]. Therefore this research is devoted to the introduction of new method which combines the silicone demulsifiers with microwave, in order to reduce the amount of silicone additives, which reflects the reduction of cost. Microwave-silicone combination might increase the efficiency, and decrease the environmental worries.

\section{MATERIALS AND METHOD}

In this project, two different crude oils from different geographical locations around the globe were donated by Malaysian oil and gas company PETRONAS (Petroliam National Berhad), a simulated experimental emulsions of various crude oils were produced to mimic the real emulsions. After massive screening, the optimal parameters to produce stable w/o emulsions were $0.25 \% \quad(\mathrm{v} / \mathrm{v})$ emulsifiers concentration (Span 80) with mixing speed of $1600 \mathrm{rpm}$ for 7 minutes, emulsions was monitored for stability within one week, then the composition of samples that had retained their water without any separation within the one week was taken as the optimal parameters to produce stable emulsion. Commercial silicon based demulsifiers were used without any further treatment. The purpose of using demulsifiers was to investigate their synergistic effect when they are used in conjunction with microwave, indeed the silicone based chemical demulsifiers are green and claimed not harmful to the environment.

Domestic microwave oven was used with little modification as depicted in the diagram (Figure 1).

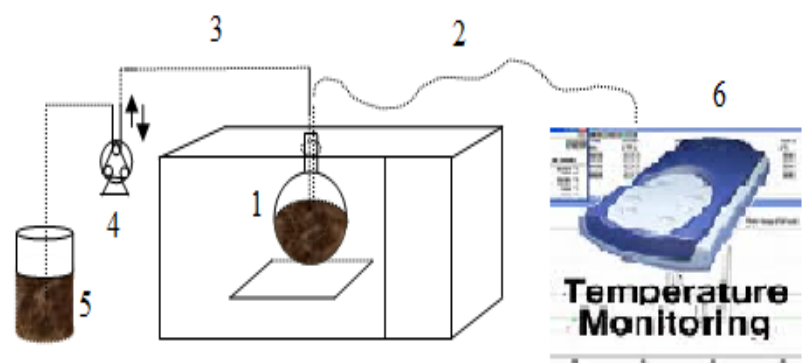

Fig 1: Microwave Dehydrator (MD)

Figure 1 is a schematic representation of the apparatus used to carry out this experimental research, 1) sample holder (Round bottom flask) inside the microwave oven, 2) thermocouple for measuring temperature, 3) hose to move the sample (emulsion) in and out, 4) peristaltic pump, 5) sample tank, 6) Pico data Logger for temperature monitoring.

The system consists of domestic microwave oven, with maximum power output of 800 watt, and $2450 \mathrm{MHz}$ frequencies, in this study, the operation frequencies were set at 800 watt, a container of $250 \mathrm{ml}$ round bottomed flask was used. A thermocouple was used to record the temperature through a Pico data logger connected to computer. After the fresh emulsion was prepared, silicon demulsifiers were added to the sample in different dosage of 0.1 and $0.05 \%$ prior to it is irradiation.

\subsection{Equations used for Data Interpretation}

Equation (1) was be used to calculate the heat generation of the treated samples, after the convective and radiation terms are eliminated it lead to equation (12).

$$
\frac{d T_{m}}{d t}=\frac{\left(q_{M W}\right)_{m}}{\rho_{m} C_{P, m}}
$$

Equation 12 is used to calculate the volume rate of heat generation. The physical properties such as density $\left(\rho_{m}\right)$ and the heat capacity $\left(C_{P, m}\right)$ of the emulsion can be calculated from the mixing rules as in equations (8) and (9). The temperature data are collected using the Picodata Loger device. 
The dielectric constant and dielectric loss of water was calculated by empirical correlations given by wolf [30].

$$
\begin{aligned}
& \varepsilon_{r^{\prime} w}^{\prime}=85.215-0.33583 T \\
& \varepsilon^{\prime \prime}{ }_{r^{\prime} w}=320.658 T^{-1.0268}
\end{aligned}
$$

Where $\varepsilon$ : Dielectric constant of water $\varepsilon^{\prime \prime}$ : Dielectric loss of water

Van Hippel proposed equation for dielectric properties of various petroleum oils, in this regard dielectric constant of crude oil for this study were calculated using equation (15)[29].

$$
\varepsilon_{r^{\prime} o}^{\prime}=2.24-0.000727 T
$$

\subsection{Measurement of Penetration Depth and} Wavelength

Gallawa reported that, there is a direct relationship between the frequency and the wavelength. There is also a relationship between the frequency and the degree or speed of heating, as well as the depth of penetration within the sample. The wavelength (which is the distance between positive peaks or negative peaks of two adjacent waves) is equal to the speed of light divided by the frequency. For practical purposes, the speed of light does not change. Therefore, the only two variables in equation are the frequency and the wavelength, their relationship as follows:

$$
\lambda_{m}=\frac{c}{f}
$$

Where: $\lambda_{m}(\mathrm{~m})$ is wavelength, $c_{\text {(ms-1) is speed of light, }}$ and $f$ is frequency $(\mathrm{Hz})$.

The above relation indicates, the higher the frequency, the shorter the wavelength, and vice versa (low frequency, corresponds to longer wavelength) [6]. Tanmay related the microwave penetration depth $D_{p}$ and wavelength of radiation in the medium $\lambda_{m}$ to dielectric constant $\varepsilon^{\prime}{ }_{r}$ and dielectric loss (loss factor) $\varepsilon^{\prime \prime} r$ via the relation given in equations (19), (20).

$$
D_{p}=\frac{c}{\sqrt{2} * \pi * f\left[\varepsilon_{r}^{\prime}\left(\sqrt{1+\left(\frac{\varepsilon_{r}^{\prime \prime}}{\varepsilon_{r}^{\prime}}\right)^{2}}-1\right)\right]^{1 / 2}}
$$

$$
\lambda_{m}=\frac{c \sqrt{2}}{f\left[\varepsilon^{\prime}{ }_{r}\left(\sqrt{1+\left(\frac{\varepsilon^{\prime \prime} r}{\varepsilon_{r}^{\prime}}\right)^{2}}+1\right)\right]^{1 / 2}}
$$

The two most common techniques for dielectric properties measurements are the resonant cavity, or cavity perturbation method, and the transmission and reflection method [28].

\section{RESULTS AND DISCUSSIONS}

Samples of water-in-oil emulsions were prepared with different ratio as described in methodology. In this study the microwave power level was fixed at the maximum of 800 watt, the irradiation time was recorded from zero to 3.5 minutes, the variables investigated were, types of crude oils used in this study and the water volume fractions (50-50 and $20-80 \%$ ), as well as the concentration of the silicone demulsifiers.

\subsection{The Temperature Profiles of Water-in-Crude}

\section{Oil Emulsions}

The experimental results of the current research would be given in the following sections. This current section is concerned about calculating and discussing the temperature profiles as well as electromagnetic parameters including dielectric properties, heat generation, and penetration depth, for water-in-crude emulsions of different crude oils.

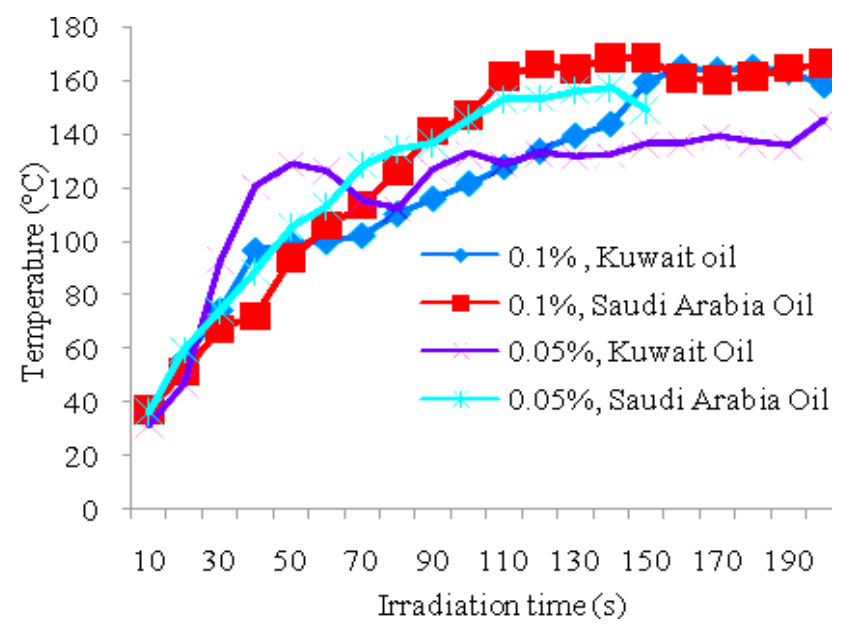

Fig 2: Temperature profiles of $50-50 \%$ w/o emulsions containing 0.1 and $0.05 \%$ demulsifiers at 800 watt and microwave irradiation time of 210 seconds.

And 


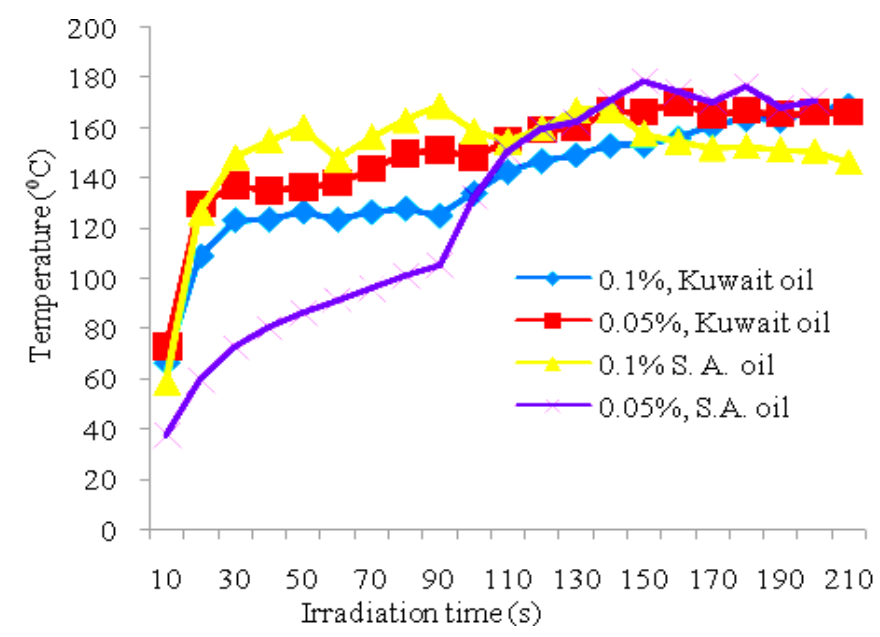

Fig 3: Temperature profiles of $20-80 \%$ w/o emulsions containing 0.1 and $0.05 \%$ demulsifiers at 800 watt and microwave irradiation time of 210 seconds.

Figures 2 and 3 reveal the data of the temperature profiles obtained in this study for two different crude oils that are originally from Middle East. Figure 2 represent high water cut of 50-50\% w/o emulsion and Figure 3 represent the low water cut of $20-80 \%$ w/o emulsions. As mentioned in the scope of this study, certain other specific parameters such as oil types, and demulsifiers' concentration on the temperature profile of the emulsions at fixed irradiation time would be discussed particularly on each figure. This is to gain some ideas on how and at what temperature the sample is being heated, indeed these experimental values of the temperature profiles would be used latter on in the modeling of system to determine the volumetric heat generation of each system as well as the wave characteristics on the sample including dielectric properties.

Based on Figure 2, at the beginning of the microwave irradiation, all emulsions had the same values of temperature which is to somehow close to the ambient temperature. But it rose very rapidly to around $50{ }^{\circ} \mathrm{C}$ in just 20 seconds, and then within the period from 20 seconds to 50 seconds each component had taken different trend. Thus the curve of the $0.1 \%$ demulsified Kuwait oil emulsion and that of the $0.05 \%$ demulsified Saudi Arabia crude oil emulsion have had almost similar trends in such a way that their gradual temperature increase as function of irradiation time had almost similar numerical values, within this period (20-50 seconds). Hence the temperature increment is ranged from around 35 to more or less $100{ }^{\circ} \mathrm{C}$ for within 20 and 50 seconds respectively.

Furthermore; $0.05 \%$ demulsified Kuwait oil sample's trend have had even greater temperature values of around $140{ }^{\circ} \mathrm{C}$, then $0.1 \%$ demulsified Saudi Arabia crude oil emulsion had the trend with the lowest temperature figure 2 . Then starting from 50 second until the end of the irradiation time, the trends were just opposite to what they were at 50 seconds. Generally all curves reached plateaus at various temperature maximum, but the difference was not that big for all samples. The maximum temperature of the 50-50\% w/o emulsions was found to be more or less $130^{\circ} \mathrm{C}$.
In more details, for $50-50 \%$ w/o emulsions, $0.1 \%$ demulsified Kuwait and Saudi Arabia oils had equal and highest temperature curve of around $150{ }^{\circ} \mathrm{C}$, then followed by $0.05 \%$ demulsified Saudi Arabian crude oil having plateau at around $145{ }^{\circ} \mathrm{C}$, then finally $0.05 \%$ demulsified Kuwait oil which had its temperature plateau at around 140 ${ }^{\circ} \mathrm{C}$. As said earlier the difference is not that big but it could be said that heating is enhanced with the increased demulsifiers $(0.1)$. On the other hand Figure 3 represents the temperature profile of $20-80 \%$ w/o emulsions, it is clear from the figure that water cut does to somehow effects the heating process, however the general trends of temperature profile were more or less similar for the two different water cuts and all samples were heated almost in the same fashion, the only strange observation is that at $50-50 \%$ w/o emulsion, the $0.05 \%$ demulsified Kuwait oil emulsion samples had the highest temperature at the beginning and lower temperature at the end.

Basically, the $0.1 \%$ demulsified Kuwait oil emulsion sample had the lowest temperature at the beginning and high temperature at the end. But for $20-80 \%$ w/o emulsions, the sample of $0.1 \%$ demulsified Saudi Arabian oil, had the maximum temperature at the beginning and minimum temperature at the end (Figures 2 and 3), but the conclusion is that the effect of demulsifiers in rising the temperature or improve the heating was observed at low water cut, in another word demulsifiers work better at low water cut.

\subsection{Rate of Temperature Increase in Emulsions}

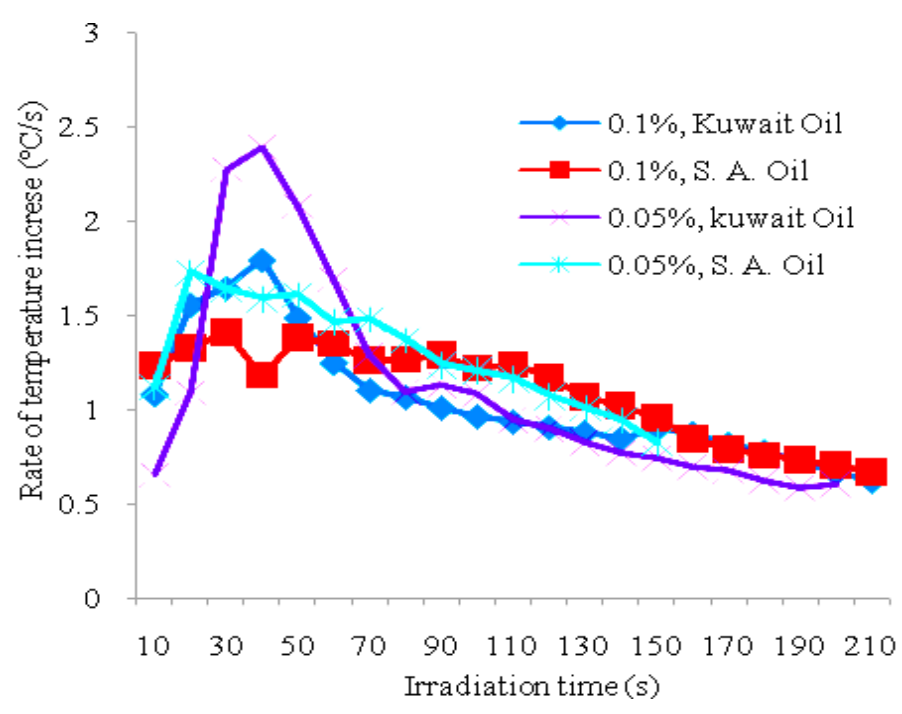

Fig 4: Rate of temperature increase vs. irradiation time for $50-50 \%$ w/o emulsions containing 0.1 and $0.05 \%$ demulsifiers at 800 watt for 210 seconds. 


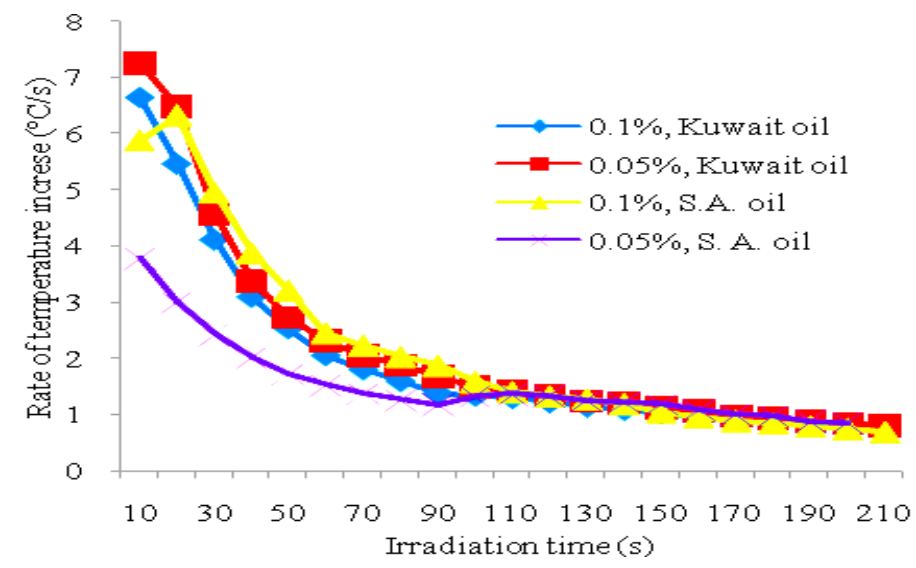

Fig 5: Rate of temperature increase vs. irradiation time for $20-80 \%$ w/o emulsions containing 0.1 and $0.05 \%$ demulsifiers at 800 watt, for 210 aeconds.

Figures 4 and 5 reveal the rate of temperature increase for $50-50 \%$ and $20-80 \%$ w/o emulsions respectively. With regard to the curves in Figure 4, almost all samples seemed to have similar trends, (increase at the beginning to some maximum values then decrease back to some plateaus), the detailed discussion of the temperature rate fluctuation with irradiation time for figure 4 could be explained by segmenting the course of the curves into three distinct regions according to their behaviors.

Region one is designated at the time interval from 0 to 20 seconds, in this interval the temperature rate was almost in linear increment with time, but $0.05 \%$ demulsified Kuwait oil had somehow slow increment value than the others at the beginning, then increased rapidly to the same levels as others as heating goes on.

Region two lies within the time interval starting from 20 to 60 seconds. In this interval, the temperature rate had experienced an increase for some samples and decrease for others, however the critical values were observed in the forms of either concave or convex that happened at $35 \mathrm{sec}$, where $0.05 \%$ demulsified Kuwait oil had the maximum values of $2.4\left({ }^{\circ} \mathrm{C} / \mathrm{s}\right)$, then followed by that of $0.1 \%$ demulsified Kuwait oil which was $1.8\left({ }^{\circ} \mathrm{C} / \mathrm{s}\right)$, unfortunately the temperature rate for Saudi Arabia oil emulsions were observed to decrease with temperature in this second interval, hence the minimum values were found to be 1.5 and $1.2\left({ }^{\circ} \mathrm{C} / \mathrm{s}\right)$, for 0.1 and $0.05 \%$ demulsified Saudi Arabia crude oils respectively.

Region three is the interval that starts from 60 seconds to the end, where all of the curves reach certain steady state values with Saudi Arabia crude oil having the highest values. Indeed Figure 5 represents the heating rate for $20-80 \%$ w/o emulsions. Generally, the heating rate was much higher than it was for $50-50 \%$ w/o emulsion. And also the highest temperature rate was observed in the very first 10 seconds, and it was $7.3\left({ }^{\circ} \mathrm{C} / \mathrm{s}\right)$, for $0.05 \%$ demulsified Kuwait oil samples, this is the sample with the highest temperature rate, in contrast $0.05 \%$ demulsified Saudi Arabia emulsion was found to possess the lowest heating rate of $4\left({ }^{\circ} \mathrm{C} / \mathrm{s}\right)$, this may be due to crude oil composition. Then $0.1 \%$ demulsified Kuwait and Saudi Arabia crude oils were found to have intermediate heating rates of 6.8 and $5.8\left({ }^{\circ} \mathrm{C} / \mathrm{s}\right)$, respectively.

\subsection{Rate of Heat Generation in Emulsions}

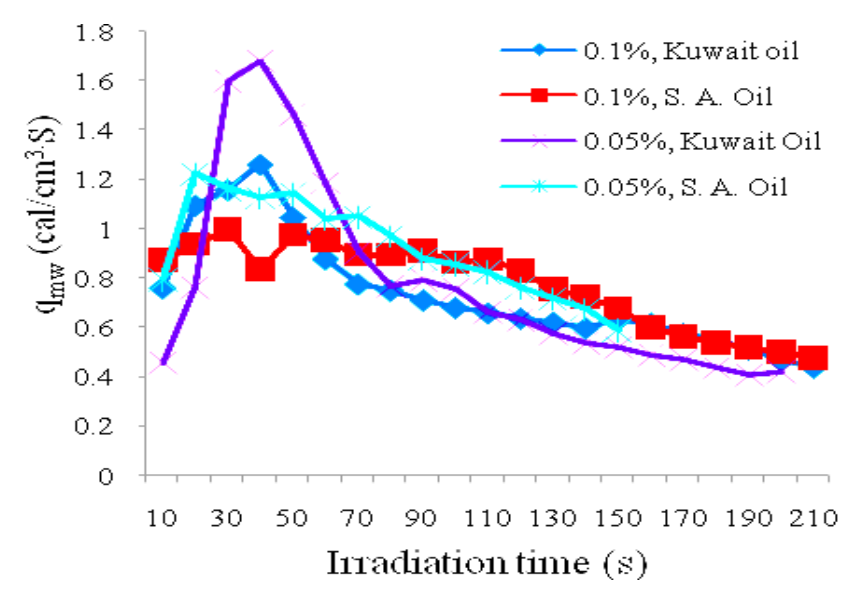

Fig 6: Volumetric rate of heat generation vs. time for 50$50 \%$ w/o emulsions containing 0.1 and $0.05 \%$ demulsifiers at 800 watt for 3.5 minutes.

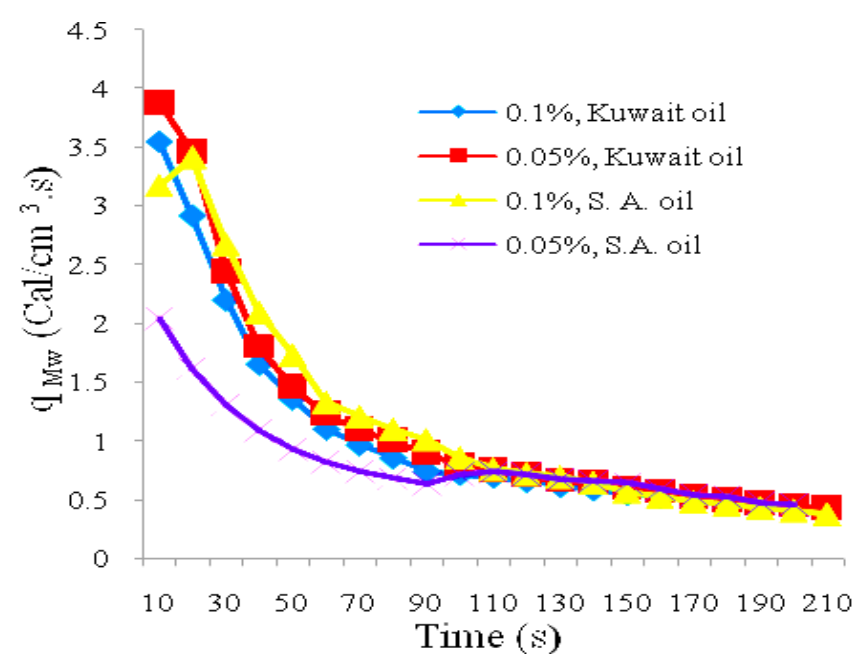

Fig 7: Volumetric rate of heat generation vs. irradiation time for $20-80 \%$ w/o emulsions containing 0.1 and $0.05 \%$ demulsifiers at 800 watt for 3.5 minutes.

The values of the volumetric rate of heat generation in figure 6 and 7 were calculated from equation 12, wherein the density and heat capacity of the mixture were determined by equations (8) and (9) respectively. Since microwave heat materials volumetrically and uniformly without temperature gradient, also the system is assumed well mixed therefore, the heat distribution within the mixture component is assumed uniform, and thus there is no temperature gradient or conductive heat transfer within the mixture components, and also the conductive term is dropped because the sample container is transparent to electromagnetic wave, and hence it generate no heat, and therefore the temperature rate was the main and varying parameter in calculating the volume rate of heat generation, and that was evidenced by the curves that had an identical 
trends as that of the temperature rates, the only difference is their numerical values which were a bit smaller reader may refer to figures $(4,5,6$, and 7$)$ to check this fact.

Generally the heating rate as well as heat generation of 50$50 \%$ w/o emulsion (higher water cut emulsions) was brought about by the influence of the water molecules, or dipole rotation while the heating rate and heat generation profiles of the $20-80 \%$ w/o (low water cut emulsion) were found to have lower temperature rate profile compared to the higher water cut (50-50\%), these samples was dominated by the ion mobility and ion concentrations, and heat is expected to be generated from the friction resulted when the rapid and random movement of ions is opposed by the viscous bulk fluid.

\subsection{Dielectric Constant vs. Temperature of Water- in-Crude Oil Emulsions}

Dielectric constant is defined as the ability of material to accommodate or obstruct microwave energy as it passes through. Is regarded as the single mechanism through which the polar and conducting material could interact with microwave that lead to the energy generation within the materials.

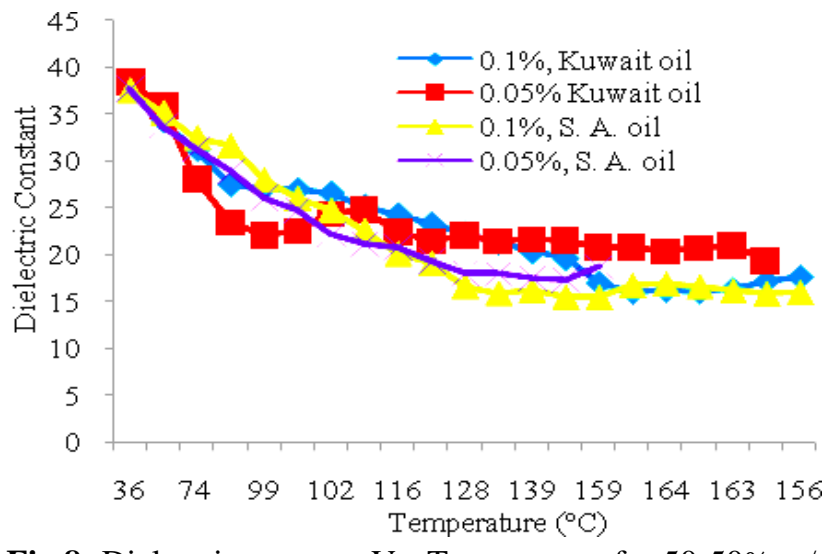

Fig 8: Dielectric constant Vs. Temperature for $50-50 \%$ w/o emulsions at $800 \mathrm{~W}$.

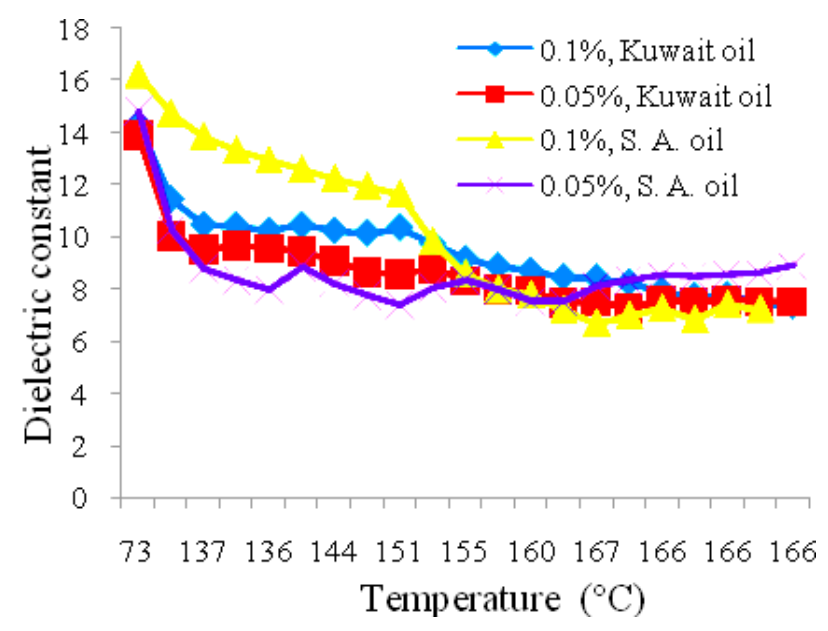

Fig 9: Dielectric constant Vs. Temperature for $20-80 \%$ w/o emulsions $800 \mathrm{~W}$.
Figures 8 and 9 contain the calculated results of the dielectric constant for 50-50 and 20-80\% w/o emulsions respectively. For $50-50 \%$ w/o emulsion all samples had similar curves, that is all started at one point which located between 35-40 (values of dielectric constant) then decreased gradually in a fluctuating pathways until they all reached a constant values of 23 (dielectric constant) more or less. When temperature reached $\left(130{ }^{\circ} \mathrm{C}\right)$, however the real steady plateau was achieved at temperature of $162{ }^{\circ} \mathrm{C}$, where $0.05 \%$ demulsified $50-50 \%$ Kuwait oil emulsion had the maximum dielectric constant values of 22) then followed the Saudi Arabian sample of the same composition having dielectric constant of 20 . The rest two $0.1 \%$ demulsified Kuwait and Saudi Arabia samples had identical dielectric constant values of 18 in that particular interval.

With regard to $20-80 \%$ w/o emulsion, the curves of all samples were found to start at almost similar values more or less 15 then immediately started to decrease, each curve was taking distinct path with $0.1 \%$ demulsified Kuwait oil having the path with the highest values of dielectric constant followed by $0.1 \%$ demulsified Saudi Arabia, and $0.05 \%$ demulsified Kuwait then $0.05 \%$ demulsified Saudi Arabia, but all paths were converged at a plateau that is seemed to have very close values of more or less 11 when temperature reached $150{ }^{\circ} \mathrm{C}$. In comparing the two curves one can conclude the following; the dielectric constant of the 50$50 \%$ w/o emulsion was higher than the dielectric constant of the $20-80 \%$ w/o emulsion and this again will consolidate the domination of the water molecules, also in 50-50\% samples, low demulsifiers' concentration gave high values of dielectric constant and the opposite was observed with the 20-80\% w/o emulsions (Figures 8, 9).

\subsection{Dielectric Loss Vs. Temperature of Water- Crude Oil Emulsions}

Dielectric loss or loss factor is a term given to the ability of conductive and polar materials to dissipate or accommodate the electromagnetic wave that is obstructed by the action of the dielectric constant, and thus help material to convert more energy in the forms of heat, and its characterized to decrease with increasing temperature as would be seen in the graphs (Figure $(10,11)$.

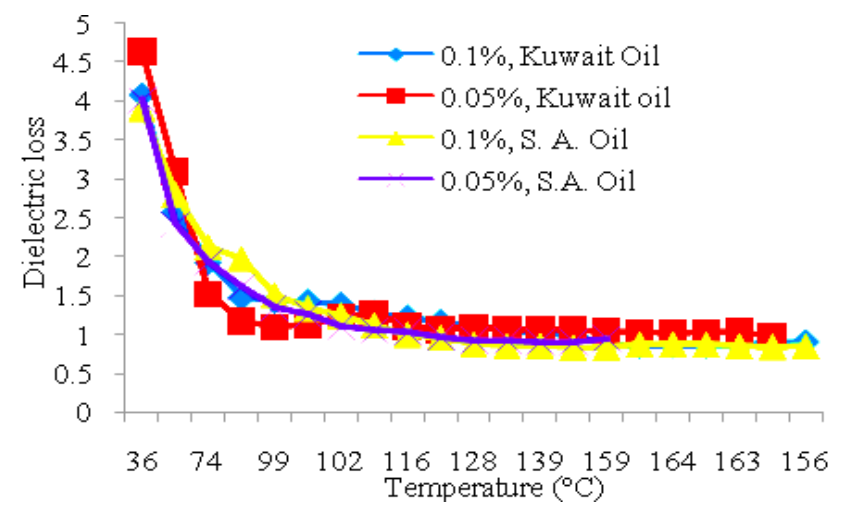

Fig 10: Dielectric Loss vs. Temperature for $50-50 \%$ w/o emulsions 


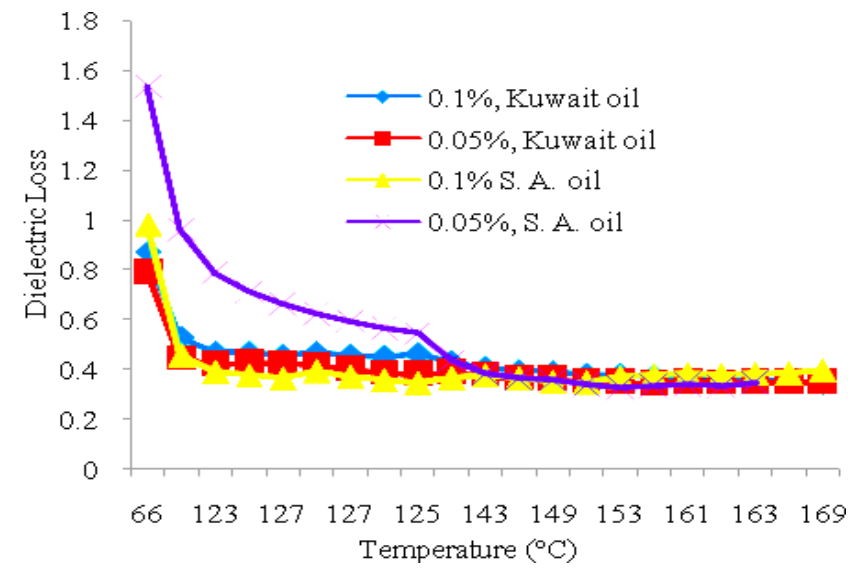

Fig 11: Dielectric constant vs. Temperature for $20-80 \%$ w/o emulsions ( $800 \mathrm{~W}, 3.5 \mathrm{~min})$

Figures 10 and11 represent the values of the dielectric loss of various samples of 50-50 and $20-80 \%$ w/o emulsions that are demulsified by various concentrations of silicone demulsifier that is used as the only demulsifier in this research. Particularly; Figure 10 represents the dielectric loss of $50-50 \%$ w/o emulsions of two crude oils, however; from first glance one can realize that not all the wave absorbed by the sample are converted to energy. This fact could be seen if one compares the values of the dielectric constant and dielectric loss of the $50-50 \%$ w/o emulsions or Figures 8 and 10, it is clear that the maximum values of the absorbed wave (Dielectric constant) was within the interval of (35-40) (Figure 8), but the maximum value of the portion that is converted to heat (dielectric loss) was within the interval of (4-5) (Figure 10), this is almost ten time reduction in the values of absorbed electromagnetic wave, that may be due the small sized sample used in this experiments.

The other observation is that the dielectric loss curves was shown to decrease sharply and reached its minimum value very fast when the sample temperature is $900 \mathrm{C}$, this is in contradiction to the dielectric constant curves whose reduction was slow and gradual, in summary it can said that dielectric constant and Loss have certain proportionality but not directly, hence more waves are dissipated but only very few are converted to energy, and this applies on the $20-80 \%$ sample as well. With regard to dielectric loss of $20-80 \% \mathrm{w} / \mathrm{o}$ emulsions, it is clear from figure 11 that all systems had almost identical values lies in the interval between (0.8-1) except $0.05 \%$ demulsified Saudi Arabia oil emulsion which have had the value of (1.6) almost double of the others, then as temperature increase, the profiles of the dielectric loss (Figure 11) had decreased gradually till they reached a constant values of $(0.4)$.
3.6 Wave Length vs. Temperature of Water-inCrude Oil Emulsions

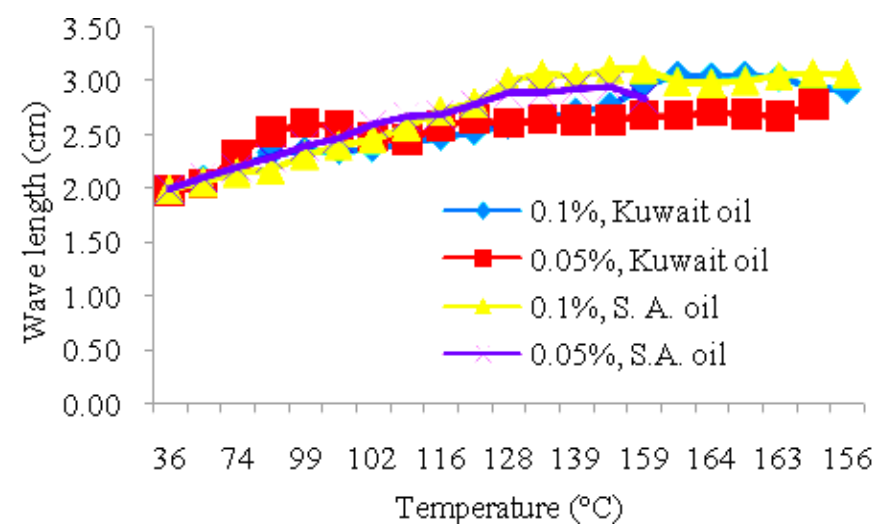

Fig 12: Wave length Vs. Temperature for $50-50 \%$ w/o emulsions $(300 \mathrm{~W})$

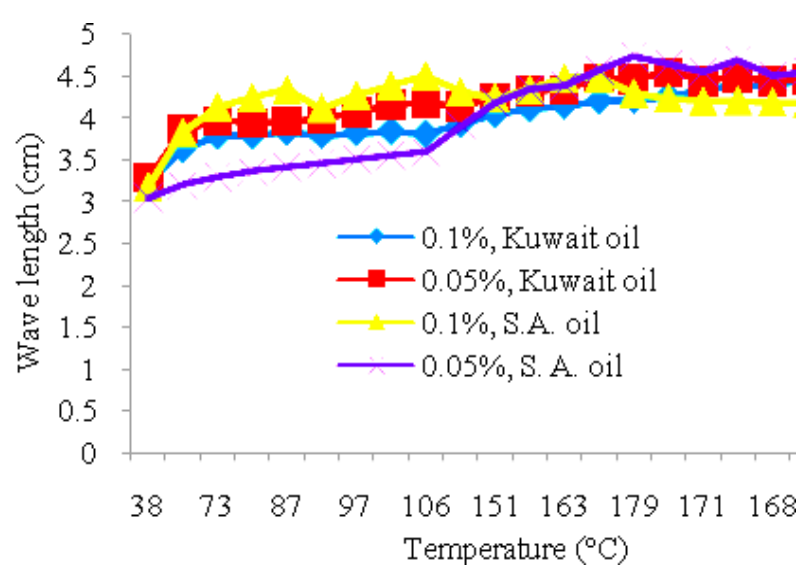

Fig 13: Wave length Vs. Temperature for $20-80 \%$ w/o emulsions (800W, $3.5 \mathrm{~min})$

Figures 12 and 13 reveal the wavelength of the microwave on $50-50$ and $20-80 \%$ w/o emulsions respectively, this is very important to know since shorter wave length would result in faster and efficient heating, indeed the wavelength also reported to vary with temperature, in fact these claims were evidenced clearly on the current result, as given in Figure 12, which showed the wavelength on samples of 50$50 \%$ w/o emulsions as function of sample temperature. Generally; all samples showed very similar profiles of the wavelength as a function of temperature the initial wavelength for all samples was almost identical and located around $2 \mathrm{~cm}$ at $36{ }^{\circ} \mathrm{C}$, and final value was $3 \mathrm{~cm}$ more or less, hence the effect of oil types as well as demulsifiers' concentration was very minor for $50-50 \%$ w/o emulsions.

With regard to $20-80 \%$ w/o emulsions, the values of the wavelength were to somehow greater than that of $50-50 \%$, but within $20-80 \%$ samples, all samples appeared to have similar wavelength. the initial value was around $3 \mathrm{~cm}$ and final value of around $4 \mathrm{~cm}$, from this results it could be said that the amount of water in the emulsion does effect much the wavelength and that may affect the heating pattern as well, since energy generation is proportional to the 
wavelength, however this research showed that, higher water content emulsion (50-50\%), could reduce the wave length to as low as $2 \mathrm{~cm}$, while it was as low as $3 \mathrm{~cm}$ on (20$80 \%$ ) emulsions, hence water in sample have an obvious effect on reducing the wavelength of the incident microwave radiation.

\subsection{Penetration Depth vs. Temperature of Water-}

\section{Crude Oil Emulsions}

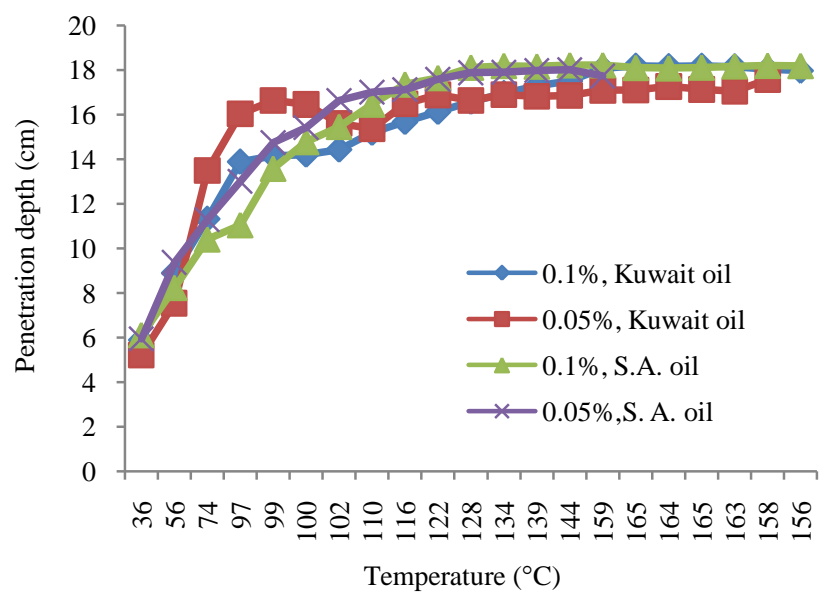

Fig 14: Penetration depth vs. Temperature for $50-50 \%$ w/o emulsions $(800 \mathrm{~W})$

Figures 14 and 15 describe the penetration depth of the electromagnetic waves on the samples of $50-50 \%$ and 20 $80 \%$ w/o emulsions respectively. The penetration depth for $50-50 \%$ w/o emulsions was found to be almost equal for all compositions, and varies with temperature. Its starting value was $5 \mathrm{~cm}$ for all samples at the very beginning of the irradiation when the temperature was just $36{ }^{\circ} \mathrm{C}$, then it increased slowly until it reached a constant value of $15 \mathrm{~cm}$ when temperature was $102{ }^{\circ} \mathrm{C}$,

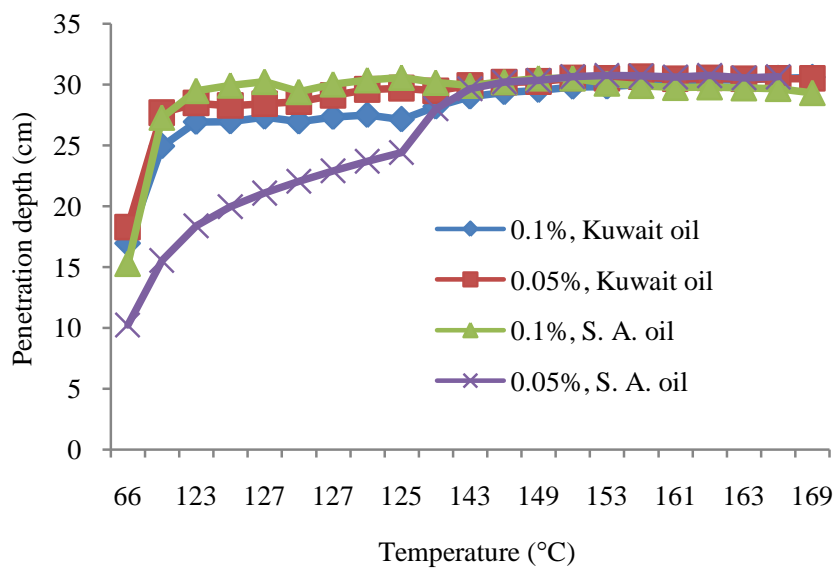

Fig 15: Penetration depth Vs. Temperature for $20-80 \% \mathrm{w} / \mathrm{o}$ emulsions $(800 \mathrm{~W})$

however comparing this result to that of $20-80 \%$ w/o emulsions of Figure 15; it is clear that water cuts does greatly affect the penetration depth, hence the difference was around two order of magnitude greater for $20-80 \%$, whose initial value was around $15 \mathrm{~cm}$ for the three samples and it was around $10 \mathrm{~cm}$ for $0.05 \%$ demulsified $20-80 \%$ Saudi Arabia (S.A) crude oil at $66{ }^{\circ} \mathrm{C}$, then increased gradually with temperature, indeed all values were converged at plateau of around $30 \mathrm{~cm}$, when temperature reached $143{ }^{\circ} \mathrm{C}$. From this observation it can be said that the actual concentration of demulsifiers does not affect much the penetration depth nor the oil type only water cut does, another information is that the penetration depth was found to increase with increasing temperature and that is to somehow in accordance with the theory which defines penetration depth as the depth where the power is reduced to $37 \%$ of the surface values, indeed Davinder have reported the gradual dependence of penetration depth on sample temperature (Davinder et al., 1997).

\section{MICROWAVE DEHYDRATION OF PETROLEUM BASED EMULSIONS}

The preceding section had discussed the demulsification process in terms of thermal properties but this section would tackle the efficiency of microwave in breaking several types of emulsions, including experimental as well as real emulsions, and the microwave performance would be assessed in terms of water resolution.

\section{EFFECTS OF DEMULSIFIERS' CONCENTRATION AND IRRADIATION TIME ON DEHYDRATION}

This section is aimed to investigate the synergistic effect of the chemical assisted microwave demulsification in terms of water separation from the stable emulsion, together with the irradiation time for 50-50 and 20-80\% w/o emulsions of Kuwait and Saudi Arabia.

\subsection{Kuwait Oil}

The effect of microwave in breaking w/o emulsions was assessed in this section, in terms percentage of water resolved from the emulsions.

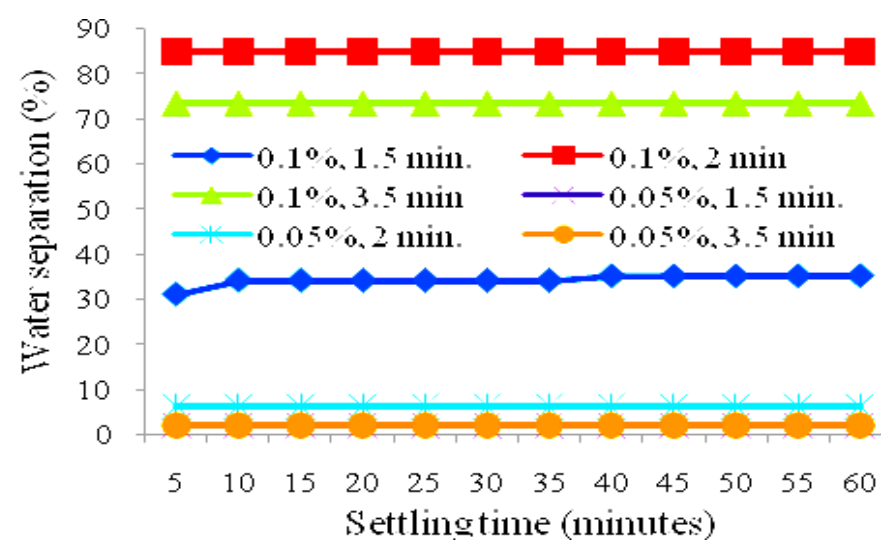

Fig 16: Percentage of water separation for $50-50 \%$ w/o emulsion (Kuwait oil) 
Figure 16 reveals the experimental results obtained from 50$50 \%$ w/o emulsions of Kuwait crude oil, as stated earlier many parameters are to be discussed in this paragraph but currently Figure 16 is particularly devoted to observe the synergistic effects of the demulsifers' concentration and Irradiation or processing time on the emulsion separation efficiency, which in turn evaluated by pouring the processed samples in measuring cylinder and the separated amount of water is read of as settled layer at the bottom of the cylinder for duration of 1 hour (settling time). Indeed two different concentrations of demulsifiers $(0.1 \%$ and $0.05 \%)$, and three different irradiation times $(1.5,2$ and 3.5 minutes) were investigated on $50-50 \%$ w/o emulsion. However; the results showed that a composition with $0.1 \% \mathrm{v} / \mathrm{v}$ concentration of demulsifiers and 2 minutes of irradiation time had given the best separation efficiency of almost $87 \%$. Then followed by sample $0.1 \%$ demulsifiers and 3.5 minutes irradiation which had a separation efficiency of around $75 \%$, on the other hand $0.05 \%$ demulsifiers concentration and 1.5 microwave exposure time were found to be non effective for $50-50 \%$ w/o emulsions (Figure 16).

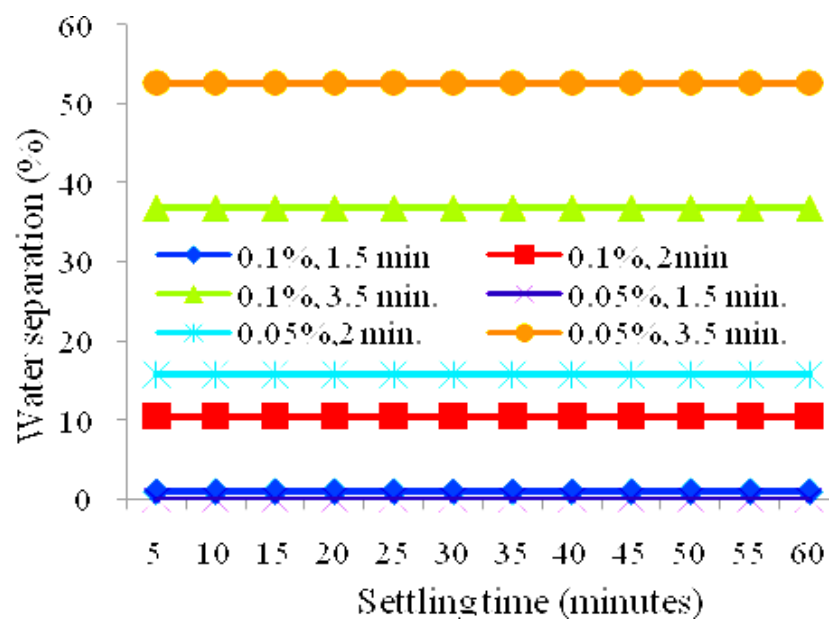

Fig 17: Percentage of water separation for $20-80 \%$ w/o emulsion (Kuwait oil)

Figure 17 was plotted to investigate the effect of water volume fraction on the emulsions, since it is well known that systems with different composition will respond differently to incident electromagnetic wave, therefore system of 20$80 \%$ w/o emulsion composed of $0.05 \%$ demulsifiers and 3.5 minute irradiation time have had the maximum water separation yield $52 \%$ more or less water resolution followed by $0.1 \%, 3.5$ minutes which had water resolution of around $37 \%$. Other interesting observation in here is that, low demulsifiers concentration had given much higher yield which was around $52 \%$ and $35 \%$ for $0.05 \%$ and $0.1 \%$ demulsified emulsions respectively, hence from this result for low water content Kuwait oil of $20-80 \%$ w/o emulsions, low demulsifiers' concentration and long irradiation time would give a better yield, so the conclusion is that the quantitative values of the parameters used to demulsify 50$50 \%$ and $20-80 \%$ w/o emulsions are just opposite to one another.

\subsection{Saudi Arabia Oil (S.A.)}

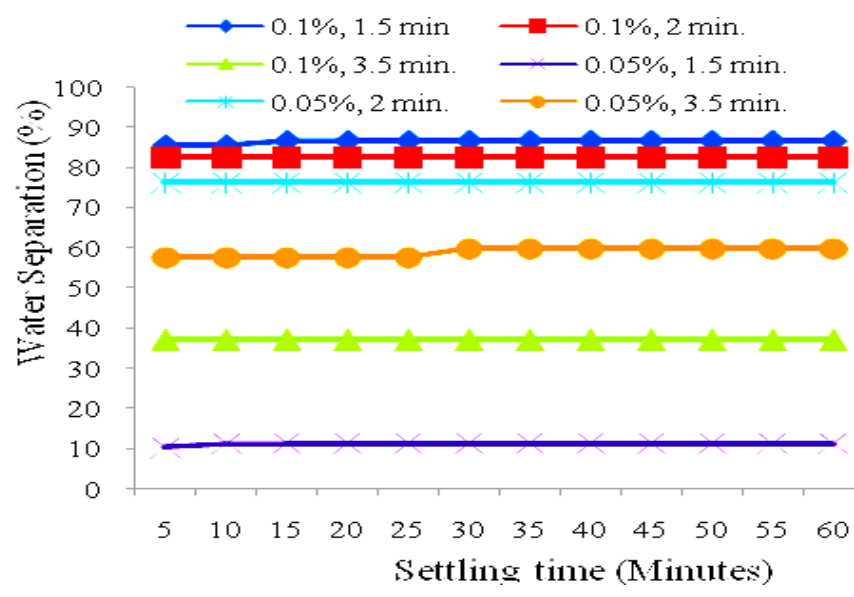

Fig 18: percentage of water separation for $50-50 \%$ w/o emulsion (Saudi Arabia oil)

Figure 18 represents the experimental results of $50-50 \%$ w/o of Saudi Arabia (S.A.) crude oil emulsions, all parameters are fixed as same as they were in Kuwait oil emulsions, so this can help to observe the effects by considering oil types as independent parameter. From these results, it was observed that the profile is almost same as it was with Kuwait oil, in a sense that high demulsifiers concentration and short irradiation time would give high yield.

From figure 18, it was observed that three samples had the highest values namely sample of $0.1 \%$ emulsifiers and 1.5 minutes irradiation had separation efficiency of around $85 \%$, but the same samples again had $82 \%$ separation efficiency when the irradiation time had increased to 2 minute; in fact this result sound ambiguous and could be attributed to the thermal properties of the samples.

The other sample with high separation yield was composed of $0.05 \%$ demulsifiers' concentration and 3.5 minutes irradiated sample which had around $59 \%$ of its water separated.

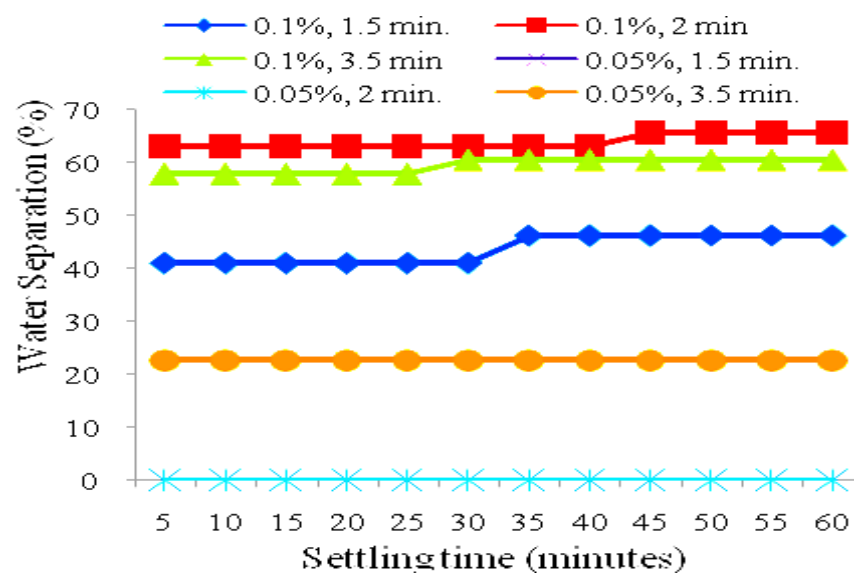

Fig 19: percentage of water separation for $20-80 \%$ w/o emulsion (Saudi Arabia oil) 
Figure 19 represents the separation efficiency for $20-80 \%$ w/o emulsions of S.A. crude oil produced using the same parameters as $50-50 \%$ emulsion, only the water content is varied purposely to observe its effect on the separation efficiency. This time the effect was in same fashion as 50$50 \%$ w/o emulsions, hence in this types of (S.A) crude oil; the water volume fraction does not affect much on the separation efficiency but demulsifiers' concentration and irradiation time do effect, hence the maximum separation efficiency of $62 \%$ was observed in sample having $0.1 \%$ demulsifiers that is irradiated for 2 minute. Indeed when the same sample irradiated further to 3.5 minutes; the separation efficiency had reduced to around $58 \%$, furthermore it was also observed in this $20-80 \%$ w/o (S.A.) crude oil that, low concentration of demulsifiers did not give much effect; this is in reverse of the $20-80 \%$ Kuwait oil in which low demulsifiers concentration and high irradiation time gave better yield (Figure 17).

\section{CONCLUSIONS}

A microwave dehydrator method was developed to treat petroleum based emulsions from crude oils that are originated from Middle East (Saudi Arabia and Kuwait). In this system, green chemical additive was used in conjunction with microwave; the advantage of this method is that the usage of chemicals are very much reduced to as low as $0.1 \%$.

In this study, experimental stable emulsion were prepared from two different crude oils (Saudi Arabia and Kuwait). The water content in the emulsion was varied $(20-80 \%$ and $50-50 \%)$, as well as the concentration of the additives $(0.05$ and $0.1 \%$ ), results was discussed in terms of, temperature, heat generation, and dielectric properties as well as water resolution.

The results of the this research showed that, for $50-50 \%$ Kuwait oil emulsions, the optimal formulation was $0.1 \%$ additive and 2 minutes irradiation time, which gave the maximum water separation of $87 \%$. While for $20-80 \%$ Kuwait oil emulsions, $0.1 \%$ additives and 2 minutes irradiation time had given the maximum separation of $52 \%$.

Furthermore, for Saudi Arabia crude emulsions, 50-50\% w/o emulsions with $0.1 \%$ additive and 1.5 irradiation time had given the maximum separation of $85 \%$. While for $20-80 \%$ w/o emulsions with $0.1 \%$ additive and 2 minutes irradiation time had given the maximum separation of $62 \%$.

The outcome of this investigation is that this newly improved method which combines the silicone based demulsifiers with microwave can consolidate the effort made by researchers to the betterment of petroleum dehydration technology, since it can reduce the amount of silicone additives, which reflects the reduction of cost. Microwave-silicone combination might increase the efficiency, and decrease the environmental worries and cost.

\section{REFERENCES}

[1]. A. N. Ilia Anisa, Abdurahman H. Nour and Azhari H. Nour, 2011, Destabilization of heavy and light crude oil emulsions via Microwave heating Technology: An optimization study, J. of Applied Science 11 (16): 28982906

[2]. Abdurahman H. Nour and Rosli M. Yunus 2006, A continuous microwave heating of water-in-crude oil emulsions: An experimental study, J. of Applied science, 6 (8): 1868-1872, 2006

[3]. Abdurahman H. Nour and Rosli M.yunus 2006, A comparative study on emulsion demulsification by microwave radiation and conventional heating, J. of Applied science 6(10): 2307-2311.

[4]. Abdurahman. H. Nour et al.,2010, Demulsification of water-in-oil emulsions by microwave heating technology, World academy of science, engineering and technology, Vol: 38-02-27.

[5]. C. Dalmazzone et al., 2005, Mechanism of crude oilinterface destabilization by silicone demulsifiers. SPE International symposium on oilfield chemistry SPE 80241 [6]. Gallawa, J.C. (1989). The Complete Microwave Oven Service, Handbook: Operation, maintenance, Troubleshooting and Repair. Library of Congress Cataloging in Publication Data

[7]. Hayder A. Abdulbari, N. H. Abdurahman, Y. M. Rosli, Wafaa K. Mahmood and H. N. Azhari 2011, Demulsification of petroleum emulsions using microwave separation method, International Journal of the Physical Sciences Vol. 6(23), pp. 5376-5382, 9 October.

[8]. Lixin Xia, Shiwei Lu, and Guoying Cao 2004, Stability and demulsification of emulsions stabilized by asphaltenes or resins, J. of Colloid and Interface Science 271 504-506

[9]. Montserrat Fortuny et al., 2007, Effects of salinity, temperature, water content and $\mathrm{pH}$ osn the Microwave demulsification of crude oil emulsions, J. of Energy and Fuels 21 1358-1364.

[10]. Rosli, M.Yunus and Abdurahman, H. Nour 2005, water-in-oil demulsification via microwave irradiation, Proceedings of the International Conference on Recent Advances in Mechanical \& Materials Engineering 30-31 May 2005, Kuala Lumpur, Malaysia Paper No.51

[11]. N. Bjorendalen et al., 2004, the effect of microwave and ultrasonic irradiation on crude oil during production with a horizontal well, J. of petroleum science and engineering 43 139- 150

[12]. Abdurahman H. Nour et al, 2012, demulsification of water-in-crude oil (w/o) emulsion via microwave irradiation: An optimization, J. of scientific research and essays, Vol. 7 (2), PP. 231-243.

[13]. Sujoy Kumar Samanta, Tanmay Basak, Bhaskar Sengupta 2008, Theoretical analysis on microwave heating of oil-water emulsions supported on ceramic, metallic or composite plates, International Journal of Heat and Mass Transfer 51- 6136-6156

[14]. Vladana Rajakovic, Dejan Skala 2006, Separation of water-in-oil emulsions by freeze/thaw method and microwave radiation, $J$. of Separation and Purification Technology 49 (2006) 192-196 
[15]. Abdurahman H. Nour, A. N. Ilia Anisa1 and Azhari H. Nour 2012, Demulsification of water-in-oil (W/O) emulsion via microwave irradiation: An optimization, J. of Scientific Research and Essays Vol. 7(2), pp. 231-243, 16 January.

[16]. Fang, C.S., and Lai, P.M.C. (1995). Microwave Heating and Separation of Water-in-Oil Emulsions, J. Microwave Power and electromagnetic energy. 30, 46-57.

[17]. Roger Meredith 1998, Engineer's Hand Book of industrial Microwave heating, the institution of electrical engineers, London, United Kingdom.

[18]. Camelia et al 1998 Dielectric parameters relevant to microwave dielectric heating, J.of Chemical Society Reviews, 1998, volume 27

[19]. Helene et al., 2009, Dielectric properties of crude oil components, j. Of Energy Fuels 2009, 23, 5596-5602: DOI: 10.1021/ef900445n.

[20]. Barringer et al., 1994 Effect of sample size on the microwave heating rate : oil vs. water, AIChE journal ISSN 0001-1541 CODEN AICEAC, 1994, vol. 40, no9, pp. 1433-1439

[21]. Montserrate et al., 2006, Effect of Salinity, Temperature, Water Content, and $\mathrm{pH}$ on the Microwave Demulsification of Crude Oil Emulsions, J. of Energy \& Fuels 2007, 21, 1358-1364

[22]. Thostenson and Chou, 1999, Microwave processing: fundamentals and applications. J. of composite PII: S1359835X (99)00020-2

[23]. Fang, C.S., Chang, B.K.L., and Lai, P.M.C. (1988). Microwave Demulsification. Chem.Eng.Comm. 73: 227233.

[24]. Austen K. Flatt, 2011, Siloxane cross-linked demulsifiers, United state pattent, US 7, 981, 979 B2.

[25]. Davinder Kaur et al., 1997, Microwave penetration depth measurements of ag-yba2cu307-6 thin films, J of Solid State Communications, Vol. 106, No. 4. Pp.23 I-234.

[26]. Sujoy Kumar samanta, Tanmay basak, 2009, J. of Food research international, 12, 1337-1350.

[27]. Christian holtze et al. 2006, The Microwave absorption of emulsion containing aqueous micro and nano droplets: A mean to optimize microwave heating, J. of colloid and interface science 302, 651-657.

[28]. Tanmay, B. (2004). Role of Resonances on Microwave Heating of Oil-Water Emulsions. AIChE.J.

[29]. Von Hippel, A.R. (1954). Dielectric Materials and Applications. MIT Press. Cambridge, MA.

[30]. Wolf, N.O. (1986). Use of Microwave radiation in Separating Emulsions and Dispersion of Hydrocarbon and water. U.S.Patent 4,582.629 